\title{
Personal Responsibility in Collaborative Lab Courses
}

\author{
Randall L. Musselman \\ Department of Electrical Engineering \\ U.S. Air Force Academy, CO
}

\begin{abstract}
While the concept has been around for some time, cooperative learning is often avoided due to the differences in students' individual levels of responsibility. This paper relates the personal experience of one instructor experimenting with cooperative learning in a microwavemeasurements lab. An overall purpose that provides continuity between weekly labs became a key ingredient to the success of this cooperative learning experiment. Student comments suggested that this experiment was indeed a success.
\end{abstract}

\section{INTRODUCTION}

In spite of the global nature of senior design projects common to most engineering curricula, many electrical engineering students are plagued by compartmentalized knowledge created by a piece-meal approach to labs. These labs are usually intended to provide hands-on experience that reinforces a series of lectures. While the goal is to integrate theory with practice, these lab exercises often become isolated procedure-driven tasks.

The University of Colorado at Colorado Springs has a one credit-hour, senior-level course entitled Microwave Measurements Lab. The course goal is to provide students with proficiency in the use of standard microwave measurement techniques and instrumentation. Historically, the course consisted of a series of labs, each requiring the student to use and characterize a specific piece of equipment. One lab might consist of cable-loss measurements, the next, directionalcoupler characterization, antenna-gain/pattern measurements, etc. The spirit of the course was to integrate theory with hands-on knowledge of microwave measurement techniques. However, like many such labs, each lab session seemed unnecessarily disjoint from the other. Dissatisfied with the outcome of teaching pieces of knowledge and hoping that some unifying purpose would emerge at the end of the semester, the individual lab objectives were replaced with an overall semester project that required the class to organize the details.

Simply stated, the overall goal was to measure every aspect of the transmit-receive propagation system in Figure 1, from signal generator to receiver, and to verify the Friis transmission equation for free-space propagation. This project required the students to become familiar with equipment such as the anechoic-chamber, signal generator, power meter, spectrum analyzer, etc., and to characterize devices such as antennas, directional couplers, and transmission lines. By only stating the overall semester objective, the class was allowed to take charge of the details and to identify the individual measurement tasks, which were required.

On the first day of the semester, the class was presented with the ill-defined measurement problem previously described. After some discussion, the class decided that one of the first tasks 


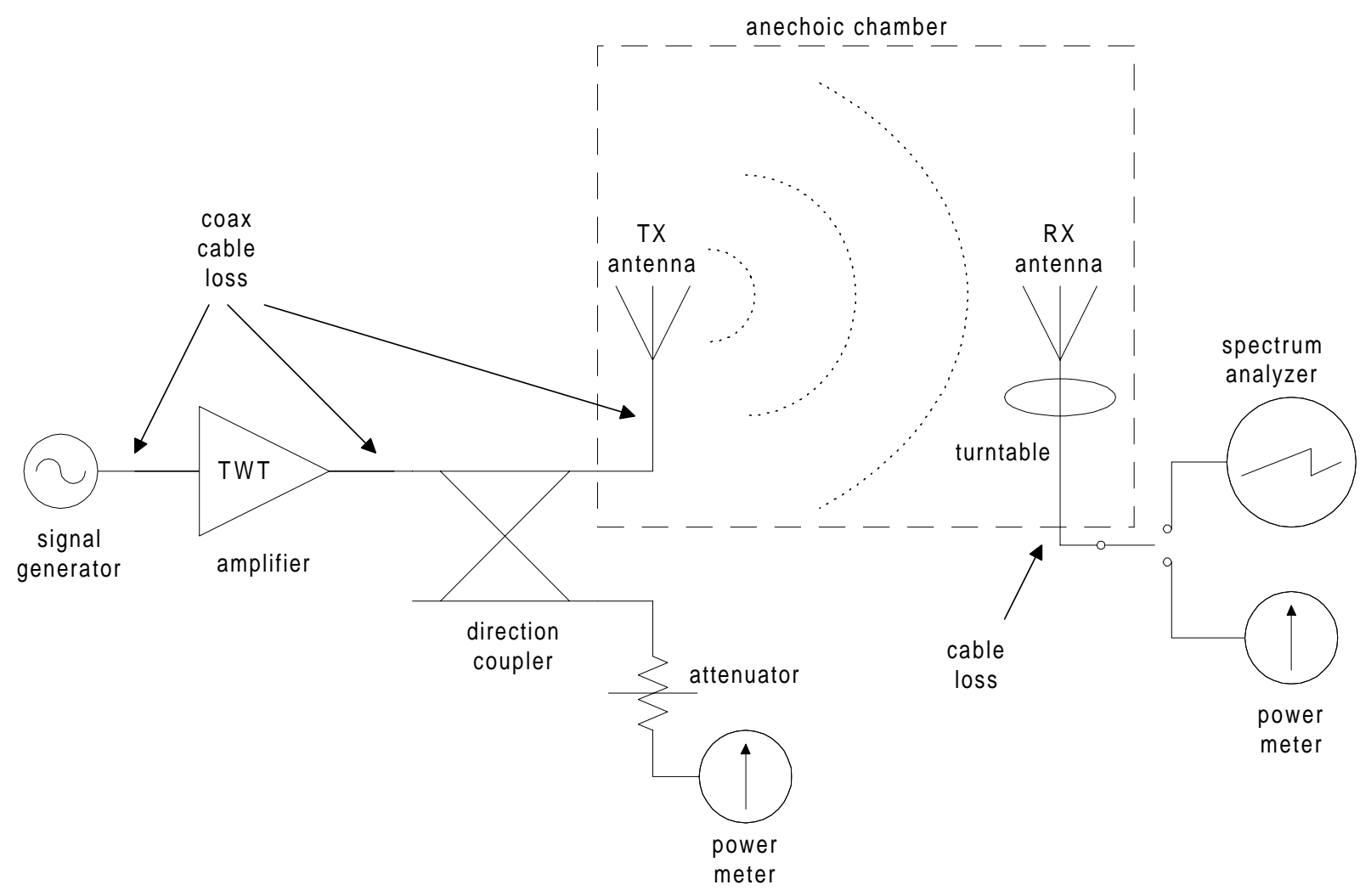

Figure 1. Transmit/receive propagation measurement system.

was to characterize cable loss versus frequency. After offering this segue, they were handed the Cable Loss lab, which can be found in Appendix A. This lab handout provided initial direction and an example to follow. It was also the last detailed task that the class was given. For the remainder of the semester, the nine students as a group created their own weekly lab descriptions along with the schedule for the semester, which can be found in Appendix B. Their efforts resulted in a course outline that was virtually identical to the one that would have been given to the class, with one important improvement. Their outline had pride of ownership, which proved invaluable in tackling the ill-defined task assigned to them.

This ill-defined goal seemed to make the course appear more as a research project than a weekly lab sequence. In many ways, this course resembled a capstone course specific to microwave engineering. Even though this course was taught in a laboratory, it dealt with very real propagation problems. In that sense, the lab offered an authentic learning experience rather than just a simulated learning experience, as defined by Dudson.[1] 


\section{COOPERATIVE LEARNING}

Originally, the course goal was to simply create an overall purpose that integrated the individual measurement tasks. The hope in leaving the overall task somewhat ill-defined, was that the students would be forced to organize and define the tasks themselves, thus forcing them to see the overall purpose. What occurred was that and more. The physical space and nature of the equipment in the lab required that all nine students work as a team. Initially, this many students in one team caused some concern. However, a group dynamic took over resulting in cooperation and student-to-student learning in a non-competitive non-threatening environment. As in many such classes, there was a wide range of backgrounds and expertise levels. Some students only had the minimum prerequisite of a course in time-varying electromagnetic field theory. At the University of Colorado at Colorado Springs, this would have consisted of a two-semester sequence of field theory. Other students were familiar with particular pieces of equipment from previous jobs and experiences. As an example, we inconveniently lost the use of our main signal generator right at the beginning of the semester. Since we were limited on signal generators operating in the microwave region, we ended up using a rather archaic signal generator with which none of us were familiar. As luck would have it, one of the students had extensively used that particular piece of equipment during his previous military experience. He taught the entire class how to proficiently use this generator. This was the first of many valuable lessons during the semester, where a student taught his or her expertise to the class. When we got ready to program several pieces of equipment for automatic measurements using the GPIB bus, it became evident that one of the students was an expert on the subject from his part-time job duties. He volunteered to teach a lesson to the class on GPIB programming. Some student-to-student learning experiences were not quite as formal as these. However, over time this dynamic began to flourish to the point that informal student-to-student learning was the norm. Some students considered themselves experts in MATLAB and were willing and eager to share their expertise. The experience reinforced what many others have found [2][3], that by allowing noncompetitive collaboration in labs, students tend to learn more.

One of the skills obtained in this course was the ability to perform power-budget calculations in decibels $(\mathrm{dB})$. Recalculating power budgets as test setups changed became a very common task. Some students became quite comfortable and proficient performing these calculations in their heads, which is one of the benefits of using $\mathrm{dB}$. Others felt more comfortable with using the algebraic form and a calculator. This made a nice mix for comparison of results. It was even amusing to observe friendly arguments being resolved as students convinced each other that large values became insignificant in $\mathrm{dB}$. Students were routinely bouncing ideas off of each other, checking each other's work in a friendly non-competitive environment. This experience gave real meaning to the term "cooperative learning."

Besides the benefit of cooperative learning, another benefit was the encouragement of personal responsibility. In spite of giving the responsibility of organizing the weekly labs to the class, one might assume that the instructor would play a dominant role, providing constant direction and correcting erroneous efforts. What became evident was that given the responsibility and the view of the big picture, the class took complete charge of their mission. Furthermore, the role of consultant and mentor became more appropriate than that of an instructor. For example, rather than characterizing a directional coupler because it was the assignment that week, the class 
characterized the coupler because they knew exactly how they would need the information in the overall measurement system. Besides providing continuity between different measurement tasks, an added bonus was the high level of enthusiasm. Students seemed to thrive on an overall project that provided meaning. This approach seemed to instill personal responsibility from the students that allowed the course goals to be met with motivation and a deeper level of understanding than would have otherwise occurred. This high level of personal responsibility created an environment that was conducive to cooperative learning.

This course contained the five basic elements of coopertive learning indicated by Howell [3] and Smith [4]:

- positive interdependence,

- face-to-face promotive interaction,

- individual accountability/personal responsibility,

- collaborative skills,

- group processing.

Positive interdependence was guaranteed by the fact that the lab had limited equipment. Face-toface promotive interaction seemed to flourish without any contrivance. When realizing that students had differing experiences and were willing to share those experiences, it became natural to simply let it happen. Initially, individual accountability and personal responsibility were the most significant concerns. However, the general attitude of the class soon put those concerns to rest. When treated as professionals, all of the students behaved as professionals, as should be expected from seniors. Most of the students already possessed collaborative skills from previous lab and study-group experiences. The nature of this class, not only encouraged collaboration, it demanded it. To promote group processing, the class periodically met on their own, without an instructor present at all. This time allowed them to discuss concepts and direction, without the risk of appearing "wrong" to the instructor. The productivity of this time became apparent when the group presented very professionally prepared status reports.

\section{STUDENT EVALUATION}

One of the problems with cooperative learning is how to evaluate individual effort. With a class size of only nine, it becomes apparent who fades into the background. The students became quite aware of this so they all took an active role in class participation. As a class, students delegated responsibilities among themselves, and a self-motivated environment prevailed. While personalities and styles differed, no real leaders dominated the class. Likewise no obvious followers let others do the work. Without teamwork, there was too much work to go around. Individual effort also became obvious when reviewing individually prepared lab notebooks. During mid-semester and end-of-semester presentations, each individual was responsible for technical questions even if it pertained to another's area of responsibility. Overall, evaluation of individual effort did not seem to present a problem in this collaborative environment. 


\section{STUDENT COMMENTS}

After the grades were turned in, and students had a semester break to think about something other than microwave measurement techniques, they were sent a questionnaire soliciting voluntary comments concerning the course. In general, their comments revealed a favorable reaction, with comments such as best lab class ever... learned more, not spoon fed. We had to be more self-motivated, which made it more difficult, but that was good, and One large project lent a sense of continuity throughout the semester that I haven't experienced in other labs. One student indicated that he liked that the instructor took a consultant's role and was there to answer questions but without overly directing.

Commenting on the structure of the course, a student responded, The structure of the class was a breath of fresh air. I know that this type of class would not work with some students, i.e., freshman; but, a class of senior EE students must be prepared for this type of environment.

Another student remarked, I liked the way the course was structured (or unstructured). As a matter of fact, I liked the fact that for the first time we were actually treated like adults and not kids as seems to be the norm.

When asked whether the required self-motivation made the course harder or easier, one student responded, By the average student's senior year, I would think that self-motivation should not be a problem and it turned out that it wasn't. For the first time in our college careers we actually got a chance to act professionally. I believe that everyone filled that role and beyond. I saw us not only getting tasks done, but as a group we had a good time also, and that was important to me.

Another student responded, I wouldn't say easier, but it was definitely easier to go to class each week.

In response to the question, "Did the self-directed nature of the course enhance or distract from the learning experience," a student answered I doubt if having weekly tasks set up for us would (have) made us learn more. As it was, we were given a semester long task to accomplish, which might have been similar to a real life situation. We knew that as long as we were on track getting the job done, we could also take time along the way to explore some other things.

Responding to this same question, a student wrote, The self-motivation, I believe, greatly enhanced our learning experience....The ability to learn for learning sake was great.

As an additional comment, one student wrote, A group of people takes on a personality of its own. By letting a structure freewheel, learning happens. The strong students learn how to teach and the weak students are bound to get an explanation that they can finally understand. At some point in time an engineer is going to get tired of looking at very small pieces of the puzzle and is going to want to see the big picture. In engineering, I think that looking at the system level is a good way to evaluate the individual pieces. 
A common criticism was class size. No one complained that nine students were too many. However, a few commented that they could not imagine having more than that on a team. Even though nine students hardly constitute a large class, it was a little cumbersome at times. In a typical lab environment, subdividing the class into smaller groups would be the obvious solution. However, the specialized nature of the equipment in this particular lab made that unfeasible. Most schools do not even have one anechoic chamber, much less several.

Another suggestion was to have an optional session just for those who had no experience with a particular piece of equipment. Even though students took turns operating and setting up the test equipment, and no prior experience with the equipment was required or expected, some students felt intimidated by the experience of others. This resulted from not anticipating the vast backgrounds that some of the more mature students would have.

\section{CONCLUSION}

A self-directed collaborative lab course requires a great deal of personal responsibility on the part of students. Furthermore, this requirement involves risks to the instructor that could cause hesitance in experimenting with alternative teaching styles. However, this class demonstrated that personal responsibility can prevail, especially when students are given a big-picture view of the overall goal. This experience seems to indicate that seniors, who are on the verge of transitioning from an academic life to a professional career, can be expected to take responsibility for organizing weekly labs for a semester-long project. In doing so, they will become accustomed to taking responsibility for their own education. Student comments suggested that treating students as professionals, and expecting them to behave so, cultivates professionalism.

\section{REFERENCES}

1. Dutson, A. J., R. H. Todd, S. P. Magleby, C. D. Sorensen, “A Review of Literature on Teaching Engineering Design Through Project-Oriented Capstone Courses," Journal of Engineering Education, vol. 86, no. 1, 1997, pp. 17-28.

2. Mourtos, N. J., "The Nuts and Bolts of Cooperative Learning in Engineering," Journal of Engineering Education, vol. 86, no. 1, 1997, pp. 35-37.

3. Howell, K. C., "Introducing Cooperative Learning into a Dynamics Lecture Class," Journal of Engineering Education, vol. 85, no. 1, 1996, pp. 69-72.

4. Smith, K. A., "The Craft Of Teaching Cooperative Learning: An Active Learning Strategy," Proceedings of the 1989 Frontiers in Education Conference, Binghamton, New York, October 15-17, 1989.

Randall L. Musselman, Ph.D., P.E., is an Assistant Professor in the Department of Electrical Engineering at the U.S. Air Force Academy. From 1995 to 1997, he taught in the ECE Department at the University of Colorado at Colorado Springs. Dr. Musselman's research interests include electromagnetic scattering, propagation modeling, and antenna design and analysis. 


\section{APPENDIX A}

ECE 4150/5150 CABLE LOSS $\quad$ (lab 2) $\quad$ FALL ‘97

\section{Objectives:}

Not all of the power generated by the source is input to the TWT amplifier. Some of the generated power is lost in the cables and connectors. Furthermore, not all of the amplified signal power enters the transmitting horn antenna. Cable loss also occurs at the receiving end.

Therefore, in this lab you will gain experience with lab equipment by measuring cable loss. You will identify all cables and connectors required for the overall free-space transmission test. This includes cable from the signal generator to bulkhead to TWT to bulkhead to TX antenna and cable from receiving antenna to power meter/spectrum analyzer. Next, you will directly measure the insertion loss of each cable with connectors at $3 \mathrm{GHz}$ and $\log$ the data in your notebooks. With an arbitrary length of similar cable, you will measure insertion loss from $1 \mathrm{GHz}$ to $18 \mathrm{GHz}$, divide by the length, and determine an insertion loss in $\mathrm{dB} / 100 \mathrm{ft}$. You will compare this to the insertion loss actually measured directly.

Equipment: (know all model numbers and record all safety and hazard parameters)

Sweep Oscillator

Power Meter

Spectrum Analyzer max. power input before damage: $300 \mathrm{~mW}(24.77 \mathrm{dBm})$ continuous, or $15 \mathrm{~W}$ $(41.76 \mathrm{dBm})$ peak for not more than $2 v \mathrm{~s}$. max. power input before damage: $30 \mathrm{~mW}(15 \mathrm{dBm})$

$$
10 \log \left(\frac{P_{\text {in }}}{1 m W}\right)=10 \log (30)=14.77 \mathrm{dBm}
$$

Test Procedure

1. Measure and record the output of the signal generator, over frequency, directly with the power meter. Record the CF\% stamped on tag. Compare to the signal generator display.

2. Perform the same as step 1, except insert a long piece of cable (use both the semi-rigid and the blue stuff) between the generator and the power meter. The difference between this reading in $\mathrm{dBm}$ and the reading from step 1 in $\mathrm{dBm}$ is the insertion loss in $\mathrm{dB}$.

3. Calculate the insertion loss for both types of cables in $\mathrm{dB} / 100 \mathrm{ft}$ over frequency. Make a pretty graph with MATLAB and post on wall of uwave lab for future reference. Label graph "Courtesy of ECE 4150/5150 Fall '97'

4. Identify and measure actual cables to be used for free-space transmission test and compare to step 3 .

5. All of this data will be used in future labs. 


\section{APPENDIX B}

ECE 415/515 Lab Schedule, Fall 1997

Orientation and equipment familiarization:

week 1

anechoic-chamber,

spectrum analyzer,

signal generator,

TWT amplifiers, power meter (calibration proc.)

IR imaging.

Lecture/theory, presentation of schedule

week 2

Cable loss measurements

weeks 3,4

Directional coupler characterization

week 5

TWT amplifier gain vs. frequency characterization

weeks 6,7 including saturation limits

Mid-semester presentation - status report

week 8 including propagation system setup.

Antenna gain/pattern measurements

weeks 9,10

develop procedure for calculating

3 unknown gains

from three antennas

(wide-band and standard-gain horns)

Setup TX/RX propagation system

week 11

Free-space propagation measurements

week 12

Discuss comparison of measured results

week 13

with Friis transmission equation, account for errors.

Multi-path measurements (conductive floor)

week 14

Compare with 2-ray model

Final presentations

weeks 15,16 